\title{
Lack of an effect of a commercial vaccine adjuvant on the development of postweaning multisystemic wasting syndrome (PMWS) in porcine circovirus type 2 (PCV2) experimentally infected conventional pigs
}

\author{
Ana RESENDES ${ }^{\mathrm{a}}$, Joaquim SEgALÉS ${ }^{\mathrm{a} *}$, Mònica BALASCH ${ }^{\mathrm{b}}$, \\ Maria CALSAMIGLIA $^{\mathrm{a}}$, Marina SIBILA ${ }^{\mathrm{a}}$, Heinz ELLERBROK $^{\mathrm{c}}$, Enric MATEU $^{\mathrm{a}}$, \\ Joan PlANA-DURÁN ${ }^{\mathrm{b}}$, Annette MANKERTZ ${ }^{\mathrm{d}}$, Mariano DOMINGO ${ }^{\mathrm{a}}$ \\ ${ }^{a}$ Centre de Recerca en Sanitat Animals (CReSA), Departament de Sanitat i d'Anatomia Animals, \\ Facultat de Veterinària, Universitat Autònoma de Barcelona, 08193 Bellaterra (Barcelona), Spain \\ ${ }^{\mathrm{b}}$ Fort Dodge Veterinaria S.A., Carretera Camprodon s/n, La Riba, 17813 Vall Bianya (Girona), Spain \\ c Robert Koch Institut, P22 Virology, Nordufer 20, 13353 Berlin, Germany \\ d Robert Koch Institut, P24 Xenotransplantation, Nordufer 20, 13353 Berlin, Germany
}

(Received 25 March 2003; accepted 17 July 2003)

\begin{abstract}
The objective of this study was to evaluate the effect of a commercial vaccine adjuvant on the clinical and pathological outcome of PCV2 experimentally infected 8 to 9-week-old conventional pigs. Forty-four pigs were divided into four groups: non-infected control pigs, pigs that received a vaccine adjuvant, pigs inoculated with PCV2, and pigs inoculated with PCV2 together with the vaccine adjuvant. Infection was monitored until 69 days post-inoculation (PI). Some PCV2 inoculated pigs had hyperthermia, but no other clinical signs were recorded. No characteristic PMWS gross or microscopic lesions were observed in any of the pigs. PCV2 DNA was detected in lymphoid tissues by in situ hybridisation in 6 PCV2 inoculated pigs on day 69 PI. All PCV2 inoculated pigs seroconverted between days 21 and 49 PI, shortly after viremia detection. Moreover, viremia was detected between days 7 and 69 PI using PCR. A peak of the virus load was detected by real-time quantitative PCR between days 14 and 21 PI. There were no significant differences in the proportion of PCV2 positive serum and in the viral load between PCV2 and PCV2 + adjuvant inoculated pigs. Although PMWS was not reproduced in neither PCV2 nor PCV2 + adjuvant inoculated pigs, viremia detection and seroconversion indicated that all PCV2 inoculated pigs developed a chronic long-term asymptomatic infection. An increase of PCV2 replication was not observed in pigs inoculated with the adjuvant. These results indicate that the principle of immunostimulation may not be applicable under the experimental conditions used, suggesting that not all adjuvants used in commercial vaccines are capable of triggering mechanisms for PMWS development.
\end{abstract}

porcine circovirus type 2 (PCV2) / pigs / vaccine adjuvant / real-time quantitative PCR / in situ hybridisation

\footnotetext{
* Corresponding author: joaquim.segales@uab.es
} 


\section{INTRODUCTION}

Porcine circoviruses include two antigenically and genomically distinct viruses of swine, namely porcine circovirus type 1 (PCV1) and type 2 (PCV2), assigned to the Circoviridae family. The virions are spherical, non-enveloped with an icosahedral symmetry. The genome consists of a singlestranded molecule of circular DNA [18, 25]. PCV2 is recognised as the cause of a clinical condition of swine named postweaning multisystemic wasting syndrome (PMWS) [2, 7, 9]. This disease mainly affects 5 to 12 week-old pigs, and is clinically characterised by growth retardation, skin pallor, dyspnea, and enlargement of the inguinal lymph nodes. Main gross findings include non-collapsed lungs, and generalised lymphadenopathy. Histological characteristic lesions of PMWS consist of lymphocyte depletion and histiocytic infiltration, often with multinucleate giant cells and amphophilic intracytoplasmatic inclusion bodies in lymphoid tissues [7, 23]. Histological lesions are systematically associated with PCV2 antigen and/or nucleic acid [23].

Koch postulates have been fulfilled for PCV2 as the primary cause of PMWS [2, 7, 10]. However, the severe clinical expression observed in field cases has been difficult to reproduce experimentally [1], suggesting that the disease is probably of multifactorial aetiology and/or that not all hosts are susceptible to the development of the disease. Experimentally, a synergistic relationship is observed when PCV2 is coinoculated with porcine parvovirus (PPV) or porcine reproductive and respiratory syndrome virus (PRRSV), resulting in a more severe expression of PMWS [2, 3, 9, $11,24]$. These studies did not elucidate the synergistic mechanism between those viruses and PCV2, but it is suggested that the activation of the cells from the monocyte/macrophage lineage by PPV and PRRSV could support an increase of PCV2 replication $[2,3]$.
The hypothesis of the immune system's stimulation by vaccines and/or vaccine adjuvants, as the key event in PMWS development is gaining acceptance, supported by some field and laboratory trials [5, 12, 14]. The use of Mycoplasma hyopneumoniae vaccines in nursery pigs together with PCV2 inoculation seems to enhance the severity of clinic and pathologic expression of the wasting disease [4, 14]. Moreover, severe PMWS expression is highly prevalent when using PCV2 infected 3-day-old gnotobiotic piglets immune stimulated with keyhole limpet haemocyanin antigen emulsified in incomplete Freund adjuvant (KLH/ICFA) with or without intraperitoneal glycan [12]. However, in the same experimental trial the use of the same immunostimulant injected IM in the neck only induced a subclinical infection [12]. Moreover, controversial results have also been observed when KLH/ICFA is administered to 3-week-old SPF pigs [15]. In evidence of these facts, the importance of vaccine adjuvants as a triggering factor of PMWS, as well as the mechanism of PCV2 replication enhancement, need to be further investigated.

The objective of this study was to evaluate the effect of a commercial vaccine adjuvant on PMWS development and PCV2 replication in 8 to 9-week-old conventional pigs, an age at which PMWS is usually observed under field conditions.

\section{MATERIALS AND METHODS}

\subsection{Animals and husbandry}

Forty-two crossbreed piglets were delivered from seven sows coming from a conventional 50-sow, farrow-to-finish operation, free of infection with PPV, PRRSV, Aujeszky disease virus, swine influenza virus, transmissible gastroenteritis coronavirus, porcine respiratory coronavirus and Actinobacillus pleuropneumoniae, Pasteurella multocida, Bordetella bronchiseptica and swine erysipelas. PMWS-like 
clinical signs were never observed on the farm. However, the farm was known to be enzootically infected with PCV2 based on previous serologic analysis. The piglets were weaned at 2 weeks of age, and moved to level 2 biosecurity facilities. Thereafter, the piglets were ear tagged and weekly monitored for decrease of PCV2 maternal antibody titres by IPMA [21]. At approximately 8-9 weeks of age, when PCV2 antibody titres were low $(\leq 1: 320)$, the pigs were divided into four groups and housed in different isolated rooms. The animals were fed ad libitum with a conventional swine growth-diet and tap water.

\subsection{Viral inoculum}

Swine kidney (SK) cells were inoculated with a tissue homogenate prepared from tissues (lymph nodes, spleen, liver and kidney) obtained from a PMWS affected pig. After two serial passages, culture supernatants were recovered, clarified by centrifugation at $650 \times g$, and further ultracentrifuged at $100000 \times g$. The viral pellet was resuspended in DMEM, titrated in noninfected SK cells $\left(10^{4.7} 50 \%\right.$ tissue culture infective dose $\left(\mathrm{TCID}_{50}\right) / \mathrm{mL}$ ), aliquoted and frozen at $-80{ }^{\circ} \mathrm{C}$ until used. This inoculum was shown to be free of PRRSV, PPV, and PCV1 by PCR.

\subsection{Experimental design}

Selected pigs were bled, weighed and rectal temperatures were taken before challenge. Fourteen pigs were intranasally inoculated with $2.5 \mathrm{~mL}$ (total dose: $10^{5} \mathrm{TCID}_{50} /$ pig) of PCV2 inoculum each (PCV2group). Another group of 16 pigs was identically inoculated with PCV2 and intramuscularly injected with $2 \mathrm{~mL}$ of an adjuvant in one side of the neck (PCV2 + ADJgroup). The adjuvant (ADJ), currently used in commercial vaccines (Fort Dodge Veterinaria S.A., Vall de Bianya, Girona, Spain), contained manitol oleic ester (Montanide 888) plus poliethoxi eter oleate (Simusol 5100) emulsified in white mineral oil (Marcol 52). Six pigs were intranasally inoculated with $2.5 \mathrm{~mL}$ of PBS (controlgroup), and the other six pigs were additionally injected with vaccine adjuvant as previously described (ADJ-group).

Clinical monitoring was done daily, and the rectal temperature was taken every 2 days until day 23 post-inoculation (PI), and thereafter at weekly intervals. Body weight and blood samples were taken weekly until the termination of the experiment. Pigs were euthanised at 69 days PI (DPI) (19 weeks of age) with an overdose of intravenous pentobarbital, followed by ex-sanguination. A complete post-mortem examination was performed in all animals, and tissue samples (lung, tonsil, inguinal and mesenteric lymph nodes, liver, kidney, spleen, ileum, and nasal turbinates) collected and fixed by immersion in $10 \%$ buffered formalin. This study met the standards of the European Guidelines for Animal Welfare and the study protocol was approved by the Comitè Etic d'Experimentaciò Animals de Fort Dodge Veterinaria S.A., Girona, Spain (Ethics Committee of Animal Experimentation of Fort Dodge Veterinaria, S.A., Girona, Spain) and the Comissió d'Experimentaciò Animal del Departament d'Agricultura, Ramaderia $i$ Pesca de la Generalitat de Catalunya, Barcelona, Spain (Committee of Animal Experimentation of Agriculture, Livestock and Fisheries Department of the Catalan Government, Barcelona, Spain).

\subsection{Serology}

PCV2 and PCV1 antibodies were determined by a previously described IPMA technique [21]. Sera dilutions were from 1:20 to $1: 20480$, making serial four-fold dilutions. For statistical analyses, serologic results were grouped as negative or positive with low titre (1:20 to $1: 80)$, intermediate titre (1:320 to $1: 1280)$, and high titre (1:5120 to $1: 20480)$. The pigs were inoculated with PCV2 when serological titres were below 1:320; this titre corresponds to 
the detection threshold of a recently published ORF2 protein-based ELISA (data not shown) [6].

\subsection{Polymerase chain reaction (PCR)}

A PCR technique was used to screen PCV2 in serum samples from all experimental pigs at all sampling times. In addition, the PCV1 genome was also screened from serum samples at day 0 PI. DNA was extracted from $0.2 \mathrm{~mL}$ of serum using a blood commercial kit (Qiagen ${ }^{\circledR}$ Inc., Valencia, CA, USA) following the manufacturer's protocol. Established protocols for PCV2 and PCV1 amplification were used as previously described [20].

\subsection{TaqMan PCR}

To quantify PCV2 DNA in PCR positive serum samples from 7, 14, 21, 49 and 69 DPI, a real-time fluorescent-probe PCR was used as previously described [24]. The assay was performed in duplicate.

\subsection{Statistical analysis}

Rectal temperatures of the different groups were compared with the Statsdirect ${ }^{\circledR}$ programme, using variance analysis with the Kruskal-Wallis test. All other statistical analysis was performed using the SAS $^{\circledR}$ system [SAS/STAT Users' Guide: Statistics, version 8 (SAS Institute Inc., Cary, N.C.)]. A mixed linear model [26] was used to detect significant differences in the evolution of body weight, serology, and TaqMan PCR results between groups. A contingency table test was used to assess homogeny of both PCV2 inoculated groups at day 0 PI, by analysing the differences in the proportion of IPMA titers in serum samples between PCV2 and PCV2 + ADJ groups. Afterwards, a generalised linear model was used to evaluate the differences in the proportion of PCR positive results between PCV2 and PCV2 + ADJ groups throughout the experimental period.

\section{RESULTS}

\subsection{Clinical signs}

Pigs from both PCV2-inoculated groups had a slight to moderate hyperthermia, ranging from 40.5 to $41.5^{\circ} \mathrm{C}$, at 5,16 and 19 DPI $(p<0.05)$. Moreover, the PCV2 + ADJ-group had a significantly higher number $(p<0.05)$ of pigs with hyperthermia $(n=10)$ compared to the PCV2-group $(n=2)$ at 19 DPI. No significant differences were observed in the evolution of body weights between the four groups. No other clinical signs were observed in any of the pigs during the experimental period.

\subsection{Gross and microscopic lesions}

Two out of 14 and 7 out of 16 pigs from PCV2 and PCV2 + ADJ groups, respectively, had a few multifocal white foci in kidney cortices. No other significant gross lesions were observed.

Characteristic PMWS microscopic lesions, such as lymphocyte depletion and histiocytic infiltration, were not found in any of the pigs at the time of examination (69DPI). Only mild to moderate multifocal interstitial nephritis were observed in some pigs from all groups.

\subsection{In situ hybridisation (ISH)}

PCV2 nucleic acid was found in the lymphoid tissues from three pigs from each PCV2 inoculated group. Scant labelling was detected in the cytoplasm of follicular dendritic-like cells of the mesenteric and inguinal lymph nodes, and tonsil.

\subsection{PCV2 and PCV1 serological results}

Seroconversion was first detected at day $21 \mathrm{PI}$ in 10 out of $14(71.4 \%)$ PCV2 inoculated pigs and in 15 out of $16(93.7 \%)$ PCV2 + ADJ inoculated pigs, with titres ranging from 1:320 to $1: 5120$. Three pigs from the PCV2-group seroconverted after day 35 PI. No differences were observed in the antibody titres evolution between 


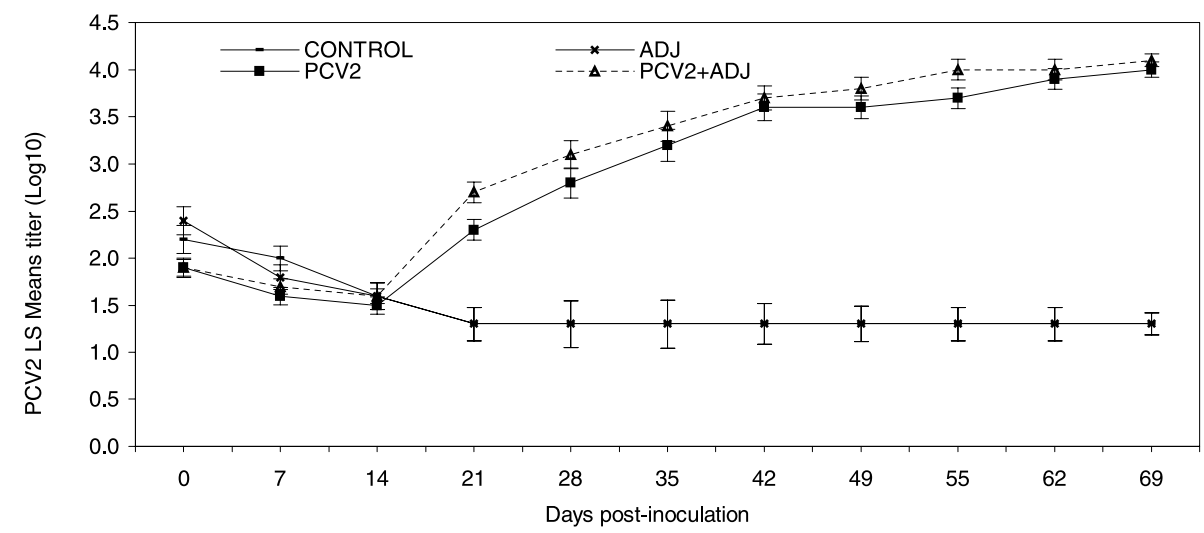

Figure 1. Dynamics of anti-PCV2 serum titres (LS Means) of pigs from the four experimental groups. LS Means Log 10 titres are equivalent to IPMA titres expressed as the inverse of the maximum dilution with reaction: $0=$ negative; $1.3=1 / 20 ; 1.9=1 / 80 ; 2.5=1 / 320 ; 3.1=1 / 1280$; $3.7=1 / 5120 ; 4.3=1 / 20480)$. Vertical bars correspond to $\pm 1 \mathrm{SD}$.

both inoculated groups. In both inoculated groups PCV2 antibody titres increased throughout the experimental period (Fig. 1). By the end of the experiment, most pigs had high antibody titres, ranging from 1:5120 to 1:20480. Neither control pigs nor the pigs inoculated with the adjuvant showed seroconversion to PCV2 throughout the experimental period. Five out of 14 PCV2 inoculated and 6 out of 16 PCV2 + ADJ inoculated pigs seroconverted to PCV1, with titres ranging from 1:320 to 1:1280, between days PI 21 and 69 .

\subsection{Serum PCV1 and PCV2 PCR}

No PCV2 amplification was detected in the serum samples from both control groups during the whole experimental period, nor in both PCV2-inoculated groups before challenge. The onset of viremia was detected in both PCV2-inoculated groups between days 7 and $21 \mathrm{PI}$ in a high proportion of the pigs. The percentages of positive serum samples are represented in Figure 2. Overall, no significant differences were observed in the dynamics of PCV2 viremia between the PCV2 and PCV2 + ADJ groups. PCV2 DNA detection persisted (intermittently or continuously) at least until 69 days PI in most pigs. Viral DNA was undetectable in two pigs from the PCV2-group, and sporadically detected in four pigs from both PCV2 inoculated groups.

The PCV1 genome was not found in any of the samples at day 0 PI.

\subsection{Serum PCV2 TaqMan PCR}

The results are summarised in Figure 3. No significant differences were observed in the serum viral load between PCV2 and PCV2 + ADJ groups. A peak of the virus load was observed between days 14 and $21 \mathrm{PI}$, in both PCV2-inoculated groups.

\section{DISCUSSION}

The present study was designed to evaluate the effect of a commercial vaccine adjuvant on the potential development of PMWS in 8 to 9-week-old conventional pigs. The age of the pigs at inoculation was chosen based on a low level of maternal antibodies, which coincided with the typical age presentation of PMWS under field conditions [22].

Under the present experimental conditions, no potentiation effect was observed 


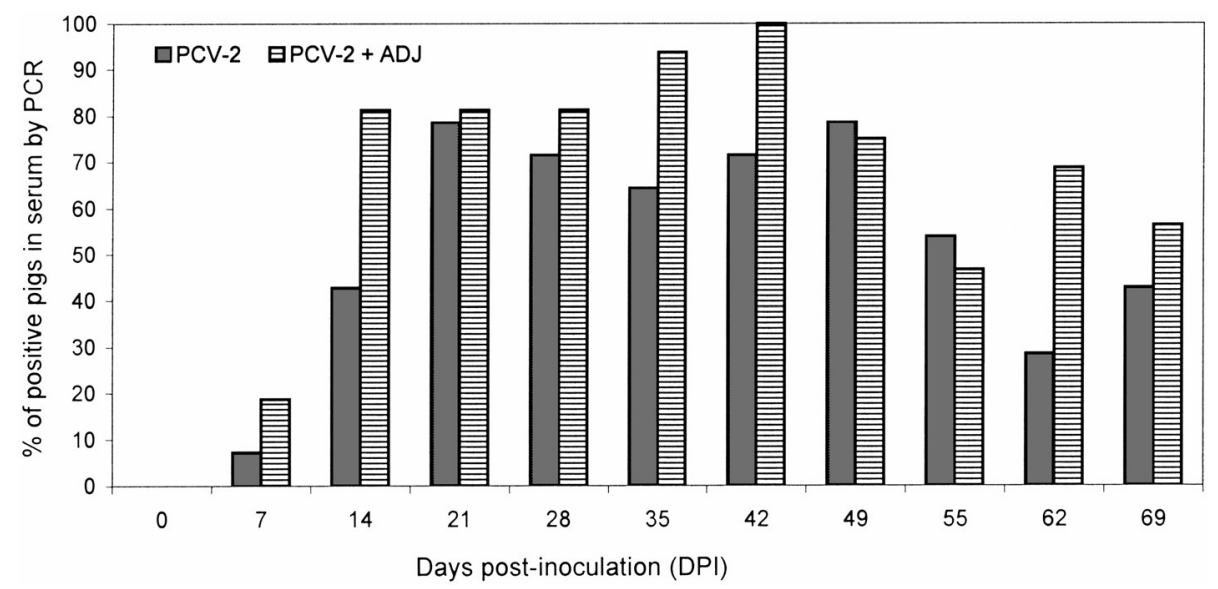

Figure 2. Percentage of positive PCV2 serum samples in both PCV2 inoculated groups (PCV2 and PCV2 + ADJ groups) throughout the experimental sampling period using PCR.

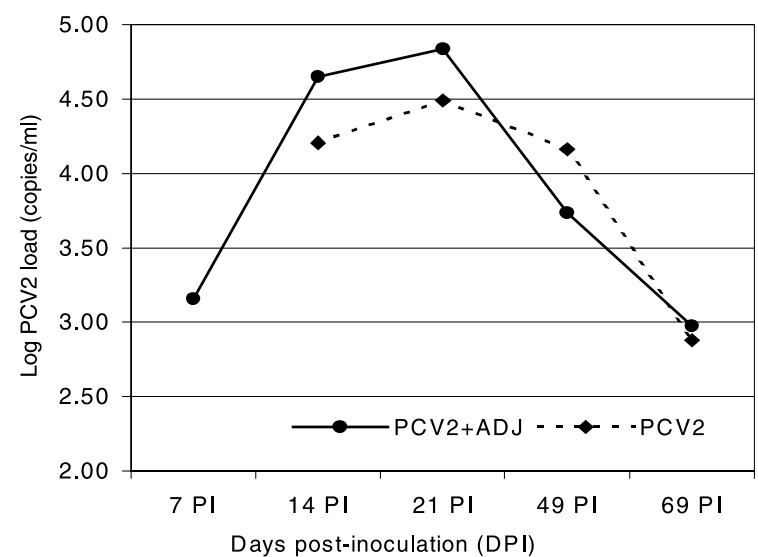

Figure 3. PCV2 genome mean coded load ( $\left.\log _{10}\right)$ using TaqMan PCR in positive PCR serum samples both in the PCV2 and PCV2 + adjuvant (ADJ) group at intervals after inoculation. by the use of the vaccine adjuvant in PCV2 replication and development of PMWS. All PCV2-inoculated pigs developed a subclinical infection, as demonstrated by seroconversion to PCV2 and the long-term viremia at least until day 69 PI. No characteristic PMWS lesions $[8,23]$ were found at the experimental termination day, despite the occasional presence of the viral genome in some lymphoid tissues. The only clinical evidence of the viral infection was an intermittent hyperthermia, between days 16 and 19 PI, which coincided with the onset of viremia and the highest viral load in the serum, which is in concordance with the results from other PCV2 experimental trials $[7,24]$.

The serological profile observed in both PCV2 inoculated groups was similar, and was in agreement with those from other experimental trials, with an increase of antibody titres occurring after 2 weeks PI, shortly after viremia detection [7, 17, 19]. Viremia coexisted with high antibody titres until the end of the experiment, which suggests that PCV2 can evade a specific immune response, or alternatively, an effective immune response was of slow development, as suggested by other authors [22]. On the contrary, seroconversion to 
PCV1 was observed in a proportion of pigs; these results were not surprising, since it is well known that serological cross-reaction between PCV1 and PCV2 exists [21]. In fact, this serological cross-reactivity between both porcine circoviruses has been observed in pigs experimentally infected with PCV2, associated to the development of seroneutralising antibodies [19].

Viremia and seroconversion were analysed and compared over time using a generalised and mixed linear model, but no significant differences were observed between the PCV2-adjuvant pigs versus the PCV2 pigs. In addition, no significant differences were observed in PCV2 viremia quantification, thus excluding any potentiation effect on viral replication by the adjuvant in this particular trial. It is known that PMWS affected pigs have a higher viral load than subclinically PCV2 infected pigs [12, 13 , $15,16,24]$. Therefore, it has been proposed that the use of products that stimulate the immune system, such as vaccines or nonspecific immunostimulators, may potentiate PCV2 replication leading to PMWS [4, $12,14]$. In the present study, the use of a commercial adjuvant in PCV2 infected pigs did not result in PMWS, suggesting that not all adjuvants used in commercial vaccines may be capable of triggering the mechanisms that potentiate PCV2 replication and generate disease. Therefore, the principle of immunostimulation may not be applicable to all different swine production systems, experimental conditions and/or host characteristics, as suggested by other authors [15]. The latter study demonstrated that $\mathrm{KLH} / \mathrm{ICFA}$ is not necessary for the induction of PMWS in 3 week-old SPF pigs. In addition, the same adjuvant does not trigger any clinical effect when applied locally in the neck of gnotobiotic PCV2 infected piglets [12]. The results of the abovementioned studies are in full agreement with the results of the present study. Therefore, the role of immune stimulation as an important key point in the outcome of naturally occurring PMWS remains to be elucidated.

\section{ACKNOWLEDGMENTS}

This work was partly funded by Projects QLRT-PL-199900307 from the European Commission and the 2-FEDER-1997-1341 from the I+D National Plan (Spain). The authors are grateful to E. Huerta, M. Mora, S. Espinar, S. Usero, B. Pérez, and P. Losada for the excellent technical assistance. To J.P. Masllopart and M. Aulines for animal care and handle. To L. Badiella from the Servei d'Estadistica de la Universitat Autònoma de Barcelona for data statistical assistance. To A. Rovira from CReSA for critical opinion and experimental sampling assistance. Finally, to C. Rosell and G. RodríguezArrioja for necropsy assistance.

\section{REFERENCES}

[1] Albina E., Truong C., Hutet E., Blanchard P., Cariolet R., L'Hospitalier R., Mahe D., Allee C., Morvan H., Amenna N., Le Dimna M., Madec F., Jestin A., An experimental model for post-weaning multisystemic wasting syndrome (PMWS) in growing piglets, J. Comp. Pathol. 125 (2001) 292-303.

[2] Allan G.M., Kennedy S., McNeilly F., Foster J.C., Ellis J.A., Krakowka S.J., Meehan B.M., Adair B.M., Experimental reproduction of severe wasting disease by co-infection of pigs with porcine circovirus and porcine parvovirus, J. Comp. Pathol. 121 (1999) $1-11$.

[3] Allan G.M, McNeilly F., Ellis J., Krakowka S., Meehan B., McNair I., Walker I., Kennedy S., Experimental infection of colostrum deprived piglets with porcine circovirus 2 (PCV2) and porcine reproductive and respiratory syndrome virus (PRRSV) potentiates PCV2 replication, Arch. Virol. 145 (2000) 2421-2429.

[4] Allan G.M., McNeilly F., Kennedy S., Meehan B., Ellis J., Krakowka S., Immunostimulation, PCV-2 and PMWS, Vet. Rec. 147 (2000) 170-171.

[5] Allan G.M., McNeilly F., McNair I., O’Connor M., Meehan B., Gilpin D., Ellis J., Townsend H., Lasagna C., Boriosi G., Krakowka S., Neonatal vaccination for Mycoplasma hyopneumonia and post-weaning multisystemic wasting syndrome: a field trial, Pig J. 48 (2001) 34-41.

[6] Blanchard P., Mahe D., Cariolet R., Truong C., Le Dimna M., Arnauld C., Rose N., Eveno E., Albina E., Madec F., Jestin A., An ORF2 protein-based ELISA for porcine circovirus 
type 2 antibodies in post-weaning multisystemic wasting syndrome, Vet. Microbiol. 94 (2003) 183-194.

[7] Bolin S.R., Stoffregen W.C., Nayar G.P., Hamel A.L., Postweaning multisystemic wasting syndrome induced after experimental inoculation of cesarean-derived, colostrumdeprived piglets with type 2 porcine circovirus, J. Vet. Diagn. Invest. 13 (2001) 185-194.

[8] Clark E.G., Post-weaning multisystemic wasting syndrome, Proc. Am. Assoc. Swine Pract. 28 (1997) 499-501.

[9] Harms P.A., Sorden S.D., Halbur P.G., Bolin S.R., Lager K.M., Morozov I., Paul P.S., Experimental reproduction of severe disease in $\mathrm{CD} / \mathrm{CD}$ pigs concurrently infected with type 2 porcine circovirus and porcine reproductive and respiratory syndrome virus, Vet. Pathol. 38 (2001) 528-539.

[10] Kennedy S., Moffett D., McNeilly F., Meehan B., Ellis J., Krakowka S., Allan G.M., Reproduction of lesions of postweaning multisystemic wasting syndrome by infection of conventional pigs with porcine circovirus type 2 alone or in combination with porcine parvovirus, J. Comp. Pathol. 122 (2000) 9-24.

[11] Krakowka S., Ellis J.A., Meehan B., Kennedy S., McNeilly F., Allan G., Viral wasting syndrome of swine: experimental reproduction of postweaning multisystemic wasting syndrome in gnotobiotic swine by coinfection with porcine circovirus 2 and porcine parvovirus, Vet. Pathol. 37 (2000) 254263.

[12] Krakowka S., Ellis J.A., McNeilly F., Ringler S., Rings D.M., Allan G., Activation of the immune system is the pivotal event in the production of wasting disease in pigs infected with porcine circovirus-2 (PCV-2), Vet. Pathol. 38 (2001) 31-42.

[13] Krakowka S., Ellis J.A., McNeilly F., Gilpin D., Meehan B., McCullough K., Allan G., Immunologic features of porcine circovirus type 2 infection, Viral Immunol. 15 (2002) $567-582$.

[14] Kyriakis S.C., Saoulidis K., Lekkas S., Miliotis C.C., Papoutsis P.A., Kennedy S., The effects of immuno-modulation on the clinical and pathological expression of postweaning multisystemic wasting syndrome, J. Comp. Pathol. 126 (2002) 38-46.

[15] Ladekjaer-Mikkelsen A.-S., Nielsen J., Stadejek T., Storgaard T., Krakowka S., Ellis J., McNeilly F., Allan G., Botner A., Reproduction of postweaning multisystemic wasting syndrome (PMWS) in immunostimulated and non-immunostimulated conventional 3-week-old piglets experimentally infected with porcine circovirus type 2 (PCV2), Vet. Microbiol. 89 (2002) 97-114.
[16] Liu Q., Wang L., Willson P., Babiuk L.A., Quantitative, competitive PCR analysis of porcine circovirus DNA in serum from pigs with postweaning multisystemic wasting syndrome, J. Clin. Microbiol. 38 (2000) 3474-3477.

[17] Magar R., Larochelle R., Thibault S., Lamontagne L., Experimental transmission of porcine circovirus type 2 (PCV2) in weaned pigs: a sequential study, J. Comp. Pathol. 123 (2000) 258-269.

[18] Mankertz A., Persson F., Mankertz J., Blaess G., Buhk H.J., Mapping and characterization of the origin of DNA replication of porcine circovirus, J. Virol. 71 (1997) 2562-2566.

[19] Pogranichnyy R.M., Yoon K.J., Harms P.A., Swenson S.L., Zimmerman J.J., Sorden S.D., Characterization of immune response of young pigs to porcine circovirus type 2 infection, Viral Immunol. 13 (2000) 143-153.

[20] Quintana J., Balasch M., Segalés J., Calsamiglia M., Rodríguez-Arrioja G.M., Plana-Durán J., Domingo M., Experimental inoculation of porcine circovirus type 1 (PCV1) and type 2 (PCV2) in rabbits and mice, Vet. Res. 33 (2002) 229-237.

[21] Rodríguez-Arrioja G.M., Segalés J., Balasch M., Rosell C., Quintana J., Folch J.M., PlanaDurán J., Mankertz A., Domingo M., Serum antibodies to porcine circovirus type 1 and type 2 in pigs with and without PMWS, Vet. Rec. 146 (2000) 762-764.

[22] Rodríguez-Arrioja G.M., Segalés J., Calsamiglia M., Resendes A.R., Balasch M., Plana-Durán J., Casal J., Domingo M., Dynamics of porcine circovirus type 2 infection in a herd of pigs with postweaning multisystemic wasting syndrome, Am. J. Vet. Res. 63 (2002) 354-357.

[23] Rosell C., Segalés J., Plana-Durán J., Balasch M., Rodríguez-Arrioja G.M., Kennedy S.M., Allan G., McNeilly F., Latimer K.S., Domingo M., Pathological, immunohistochemical, and in-situ hybridization studies of natural cases of post weaning multisystemic wasting syndrome (PMWS) in pigs, J. Comp. Pathol. 120 (1999) 59-78.

[24] Rovira A., Balasch M., Segalés J., Garcia L., Plana-Durán J., Rosell C., Ellerbrok H., Mankertz A., Domingo M., Experimental inoculation of conventional pigs with porcine reproductive and respiratory syndrome virus and porcine circovirus 2, J. Virol. 76 (2002) 3232-3239.

[25] Tischer I., Gelderblom H., Vettermann W., Koch M.A., A very small porcine virus with a circular single stranded DNA, Nature 295 (1982) 64-66.

[26] Verbeke G., Molenberghs G., Linear mixed models for longitudinal data, Springer-Verlag, New York, 2000. 